\title{
Propuesta para una Delimitación Geográfica Integral del Manglar de Nosara, Guanacaste, Costa Rica
}

\section{A Proposal for a Comprehensive Geographical Delimitation of the Mangrove of Nosara, Guanacaste, Costa Rica}

\author{
Iván Sanabria-Coto ${ }^{1}$ \\ Instituto Geográfico Nacional, Costa Rica \\ Milagro Carvajal-Oses ${ }^{2}$ \\ Universidad Nacional, Costa Rica \\ Rooel Campos-Rodríguez ${ }^{3}$ \\ Instituto Tecnológico de Costa Rica \\ Paola Solera-Steller ${ }^{4}$ \\ Instituto Tecnológico de Costa Rica
}

http://dx.doi.org/10.15359/rgac.61-2.11

\footnotetext{
1 Máster en Gestión de Recursos Naturales, geólogo del Instituto Geográfico Nacional del Registro de la Propiedad de Costa Rica. Correo electrónico: isanabria@rnp.go.cr/isanac81@gmail.com

2 Máster en Gestión de Recursos Naturales, académica de la Escuela de Ciencias Biológicas, Universidad Nacional de Costa Rica en el Programa del Parque Marino del Pacífico. Correo electrónico: milagro.carvajal.oses@una.cr

3 Doctor en Ciencias Naturales para el Desarrollo, investigador de la escuela de Agronegocios Tecnológico de Costa Rica. Correo electrónico: rocampos@tec.ac.cr

4 Máster en Biotecnología, académica de la Escuela de Biología, Tecnológico de Costa Rica. Correo electrónico: psolera@tec.ac.cr
} 
Iván Sanabria-Coto, Instituto, Milagro Carvajal-Oses, Rooel Campos-Rodríguez, Paola Solera-Steller. A Proposal for a Comprehensive Geographical Delimitation of the Mangrove of Nosara, Guanacaste, Costa Rica

\title{
RESUMEN
}

El estudio de las características del contexto fisiográfico de una región; apoyado con sistemas de información geográfica, insumos de percepción remota, y modelos de elevación digital; permite analizar la distribución horizontal de especies vegetales de un manglar, coadyuvando con su delimitación geográfica. El actual trabajo demuestra que existen potenciales condiciones fisiográficas para la expansión del manglar en Nosara; por lo que su actual delimitación, por medio de mojones, podría ser superada debido a la adaptabilidad vegetal, resultado del futuro incremento del nivel del mar y por ende se recomienda un área geográfica adicional que ejerza una función dentro de los planes maestros costeros como una zona de amortiguamiento, que no solo facilite la migración adaptativa (resiliencia) de las especies vegetales del manglar, sino que permita a su vez crear planes de manejo para el futuro.

Palabras clave: Nosara, manglar, fisiográfico, geomorfología, amortiguamiento

\begin{abstract}
Studying the characteristics of the physiographic context of a region, supported with geographic information systems, remote sensing inputs, and digital elevation models, allows to analyze the horizontal distribution of plant species of a mangrove, and this contributes its geographical delimitation. This paper shows that there are potential physiographic conditions for the expansion of the mangrove in Nosara. Thus, its current delimitation, by means of landmarks, could be overcome due to plant adaptability resulting from the future increase in sea level. Therefore, an additional geographical area is recommended to play a role within the coastal master plans as a buffer zone that not only facilitates the adaptive migration (resilience) of the vegetal species of the mangrove but also allows the creation of management plans for the future.
\end{abstract}

Keywords: Nosara, mangrove, physiographic, geomorphology, buffer zone.

\section{Introducción}

Los manglares son ecosistemas costeros que se encuentran en zonas entre mareas de las regiones tropicales y subtropicales. Taxonómicamente, consisten en un grupo diverso de comunidades leñosas pertenecientes a varias familias de angiospermas, no relacionadas entre sí, con adaptaciones especiales a condiciones salinas (Samper-Villarreal y Silva-Benavides, 2015; Benavides-Varela, Samper-Villarreal, Cortés, 2016). Los manglares tienen la capacidad de responder a procesos geomorfológicos y a interacciones continuas con otros ecosistemas contiguos en el mosaico regional, que les permite migrar hacia arriba o abajo desde la zona intermareal. Sin embargo, cuando los paisajes costeros se fragmentan por transformaciones humanas de los entornos regionales y costeros, los manglares son menos autosuficientes (Berger et al., 2008; Valverde, González, Piedra, García, 2016).

Costa Rica tiene importantes áreas de manglar en las costas del Pacífico y Caribe, la mayor parte (99 \%) se encuentra en la costa del Pacífico, 
Iván Sanabria-Coto, Instituto, Milagro Carvajal-Oses, Rooel Campos-Rodríguez, Paola Solera-Steller. Propuesta para una Delimitación Geográfica Integral del Manglar de Nosara, Guanacaste, Costa Rica

principalmente, en el Golfo de Nicoya y en el Golfo Dulce (Zamora-Trejos y Cortés, 2016). Las delimitaciones geográficas de los manglares costarricenses están estrechamente relacionadas con la Zona Pública (ZP), así lo indica el artículo N. ${ }^{\circ} 11$ de la Ley sobre la Zona Marítimo Terrestre (ZMT) N. ${ }^{\circ} 6043$ (1977) y, además añade que será el Instituto Geográfico Nacional de Costa Rica (IGN) el ente encargado de estas delimitaciones geográficas.

El IGN de acuerdo al Decreto N. ${ }^{\circ} 36$ 642-MP-MOPT-MINAET (2011), utiliza dos metodologías básicas para realizar las delimitaciones, los mojones que corresponden a estructuras de piedra georreferenciadas que limita la ZP como franja de $50 \mathrm{~m}$ a partir de la curva de nivel de $1,5 \mathrm{~cm}$, o utilizando delimitación digital georreferenciada; la cual limita la pleamar ordinaria a partir de coordenadas del sistema de referencia oficial del país.

Específicamente, el manglar Nosara se encuentra identificado en el Mapa de Tipos de Bosque de Costa Rica del Ministerio de Ambiente, Energía y Telecomunicaciones (MINAET) (2013), y delimitado físicamente (amojonado), como parte de la ZP de la ZMT por parte del IGN (Gaceta Digital N. ${ }^{\circ}$ 20, 2009). Su actual forma de delimitación impide evaluar la posible adaptabilidad ecológica del manglar ante la respuesta de la creciente en el nivel del mar (Valverde et al., 2016).

El Manglar Nosara, al igual que otros manglares, se caracteriza por su importancia ecológica y económica, su riqueza natural y los servicios ecosistémicos que prestan (Costanza y Folke, 1997; Tuan Vo, Oppelt, Leinenkugel, Kuenzer, 2013; Benavides-Varela et al., 2016). No obstante, son amenazados por la contaminación, la deforestación, la fragmentación, aumento en el nivel del mar y se les está dando otros usos de tierra como agricultura o infraestructura (Giri et al., 2010).

El objetivo de este trabajo consiste en analizar elementos fisiográficos propios del contexto marino/continental que favorecen la adaptación y distribución del manglar de Nosara, permitiendo sentar bases para una delimitación más integrada de los manglares de Costa Rica.

\section{Área de estudio}

El área de estudio correspondió a un polígono de $16,4 \mathrm{~km}^{2}$ en las cercanías del poblado de Nosara, cantón de Nicoya, provincia de Guanacaste, Pacífico Norte de Costa Rica. Con las coordenadas oficiales CRTM05: 313589-318416 Longitud Oeste y 1102000-1105206 Latitud Norte en la 
Iván Sanabria-Coto, Instituto, Milagro Carvajal-Oses, Rooel Campos-Rodríguez, Paola Solera-Steller. A Proposal for a Comprehensive Geographical Delimitation of the Mangrove of Nosara, Guanacaste, Costa Rica

hoja cartográfica Garza 3045-I escala 1:50 000 del Instituto Geográfico Nacional (Sistema Nacional de Información Territorial, 2017) (Figura 1).

Figura 1. Ubicación del área de estudio (polígono en rojo) para la investigación.

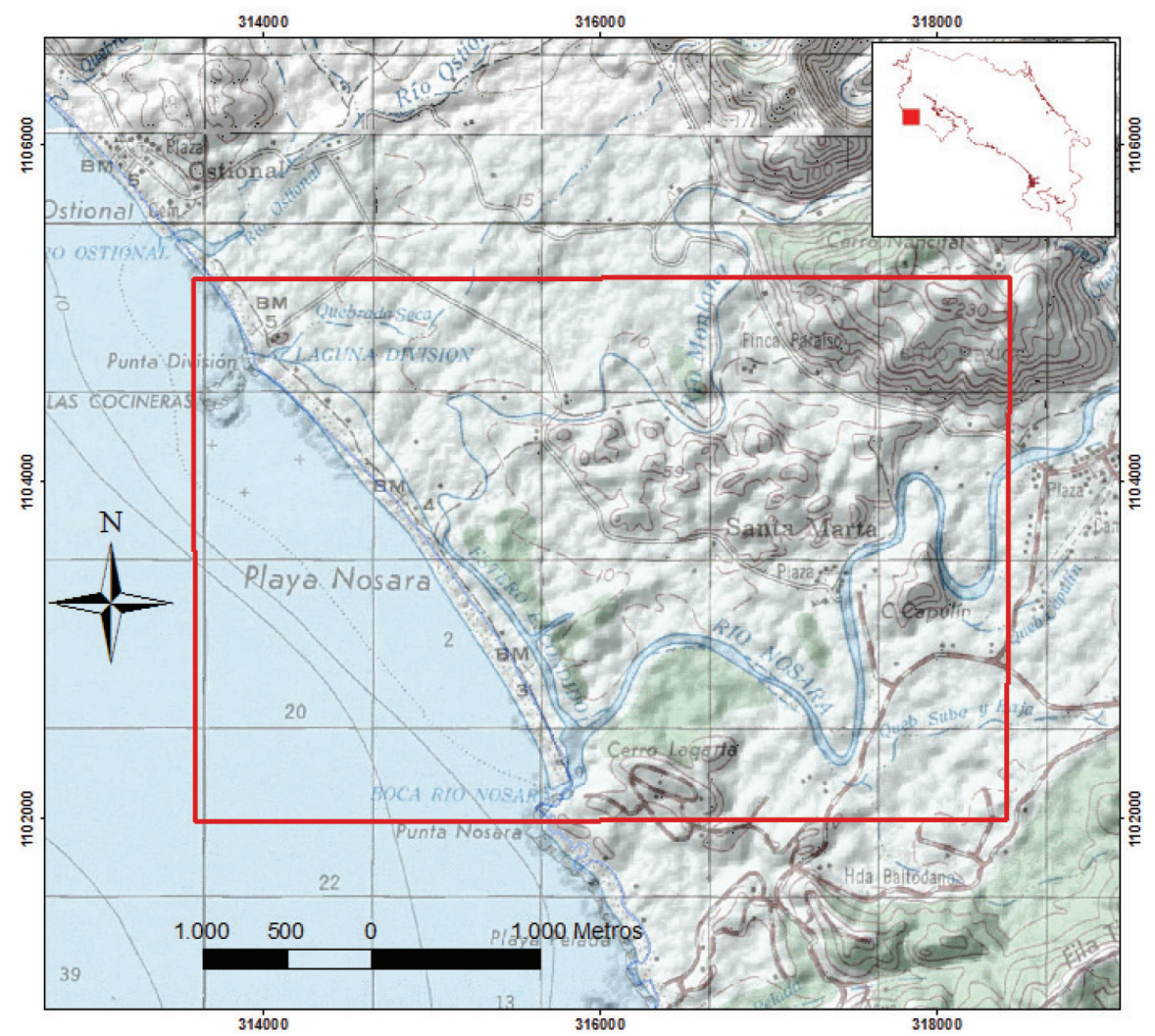

Fuente: Hoja cartográfica Garza 3045-I escala 1:50 000 del Instituto Geográfico Nacional (SNIT, 2017).

El área del Manglar Nosara se caracteriza por poseer un amplio aporte superficial de aguas continentales de ríos y quebradas, siendo el Río Nosara el curso principal del sistema hidrográfico del mismo nombre y se une en la parte baja de la cuenca hidrográfica (área de estudio) con los ríos Montaña y Quebrada Seca. Existen pocas variaciones térmicas durante el año, en las cuales las temperaturas máximas se presentan en los meses de marzo y abril (no más de $30^{\circ} \mathrm{C}$ ) y las mínimas $\left(19^{\circ} \mathrm{C}\right)$ entre diciembre y enero (Hernández, 2010b). 
Iván Sanabria-Coto, Instituto, Milagro Carvajal-Oses, Rooel Campos-Rodríguez, Paola Solera-Steller. Propuesta para una Delimitación Geográfica Integral del Manglar de Nosara, Guanacaste, Costa Rica

Características geológicas y tectónicas generales del área de estudio

El área de estudio se caracteriza por la presencia de sedimentos no consolidados de características cuaternarias (recientes) y de unidades de rocas asociadas con las formaciones geológicas sedimentarias de Santa Teresa, Punta Pelada y Arió (Denyer, Aguilar, Montero, 2014). Cabe señalar, que en periodos intermedios a los eventos sísmicos se ha observado también un progresivo hundimiento costero, lo cual puede también manifestarse por estructuras tectónicas locales con movimiento vertical como, por ejemplo, el "Pull-Apart" de Nosara. Importantes estructuras tectónicas asociadas con el área de Nosara están relacionadas con fallas activas o reconocidas como neotectónicas, las cuales por su tipo de deformación reciente provocan cambios evidentes en el terreno (Denyer, Montero, Alvarado, 2009; Denyer et al., 2014; Montero y Denyer, 2014).

En general, el Pacífico Norte se caracteriza por poseer calizas someras, bioclásticas y arrecifales con abundantes rudistas en posición vital, con presencia de poco desarrollo kárstico, principalmente, disolución en la superficie, evidenciado en una topografía irregular (Ulloa, Aguilar, Goicoechea, Ramírez, 2011).

\section{Marco teórico conceptual}

\section{Los manglares en función del contexto fisiográfico existente}

Las configuraciones de los manglares están determinadas por unidades morfodinámicas, las cuales incluyen tanto los componentes geofísicos y geomórficos del área como el grupo de especies presentes (SchaeffeNovelli, Cintrón-Morero, Soares, De-Rosa, 2000). Woodroffe et al. (2016) añade que estos ecosistemas están limitados a un rango de elevación estrecho con la marea, donde el alcance de tales hábitats intermareales (espacio de alojamiento) están en función de la etapa, madurez y complejidad geomorfológica de un área en particular.

La distribución de los bosques de manglar está influenciada en gran parte por factores como tipo de suelo, pendiente, inundación mareal y escorrentía; donde esas fuerzas ambientales que actúan varían en periodicidad e intensidad (Delgado, Hansel, Jiménez, Day, 2001; Samper-Villarreal y Silva-Benavides, 2015). Así mismo, se pueden sumar otras condiciones como la hidrodinámica, flujos de sedimentos, características orgánicas y 
geoquímicas del sustrato; donde los sedimentos que se han acumulado en el contexto geográfico registran aspectos de la historia y la dinámica geomorfológica a más largo plazo (Woodroffe et al., 2016).

En muchos ecosistemas de manglares aún no perturbados, algunos criterios fisiográficos a menudo causan una gran diferenciación en la composición de las especies vegetales y su estructura a través de transectos relativamente cortos $(10-100 \mathrm{~m})$; manglares de alta diversidad, como los que se encuentran en las zonas costeras tropicales del norte de Australia, Papua Nueva Guinea e Irian Jaya pueden contener hasta 30 especies diferentes, ampliamente segmentadas en zonas de manglares (Held, Ticehurst, Lymburner, Williams, 2010).

\section{Insumos percepción remota para la investigación del contexto fisiográfico existente en áreas de manglar}

Las herramientas para detección remota ofrecen un mapeo de alta resolución espacial, un alto contenido de información para proporcionar una buena diferenciación de las diversas zonas y tipos de manglar (Held et al., 2010), y permiten analizar cambios en la vegetación a través de un periodo de tiempo (Lee y Yeh, 2009).

Oyola (2009) recomienda el uso de la teledetección y los Sistemas de Información Geográfica para la cartografía de zonas húmedas donde los usos de sensores remotos han probado ser útiles en estudios ecológicos, de hidrología y geomorfológicos.

\section{Marco técnico/legal asociado con la identificación de elementos fisiográficos mínimos, para la delimitación de áreas de manglar en Costa Rica}

A nivel de Costa Rica existe un marco técnico/legal dedicado a estudios referentes a delimitaciones de las áreas de manglar (Figura 2), el cual permite identificar los aspectos fisiográficos necesarios para las delimitaciones de estos ecosistemas o en su defecto reajustar las existentes. 
Figura 2. Marco técnico/legal para elección de criterios fisiográficos mínimos en la delimitación de los manglares.

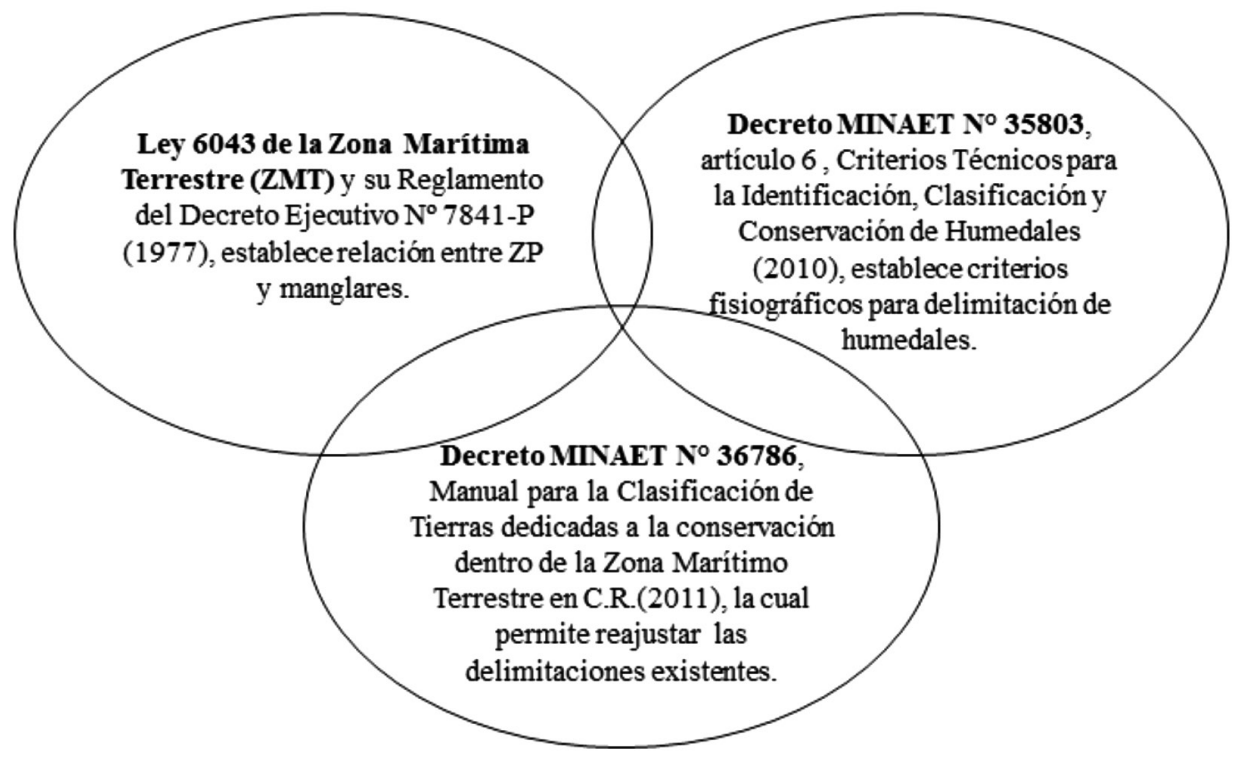

\section{Marco Metodológico}

El desarrollo de la investigación se llevó a cabo entre los meses de junio del 2016 a agosto del año 2017. El trabajo se subdividió en tres secciones, primeramente, se recolectó información, basada en trabajo de campo y compilatoria de los elementos fisiográficos necesarios para delimitar el manglar de Nosara, seguidamente, se realizó un análisis; mediante Sistemas de Información Geográfica (SIG) de los insumos de percepción remota de dicha información y, finalmente, se efectuó una validación de campo.

\section{Recolección de información de elementos fisiográficos}

Se utilizaron imágenes de fotos aéreas provenientes del Mosaico Proyecto BID-Catastro escala 1:20 000 del año 2007 (SNIT, 2017), y por medio del software Arcgis $10.3{ }^{\circledR}$ se definieron sistemáticamente los sitios de levantamiento de la información correspondiente a los elementos fisiográficos del área seleccionada (Cuadro 1). Para este efecto se adaptó parte de la propuesta metodológica de la Organización de las Naciones Unidas para la alimentación y la agricultura (FAO) (2004), en la cual se definieron 14 áreas de $1 \mathrm{~km} \times 1 \mathrm{~km}\left(1 \mathrm{~km}^{2}\right)$, cada una con cuatro parcelas de campo. 
Iván Sanabria-Coto, Instituto, Milagro Carvajal-Oses, Rooel Campos-Rodríguez, Paola Solera-Steller. A Proposal for a Comprehensive Geographical Delimitation of the Mangrove of Nosara, Guanacaste, Costa Rica

Las parcelas se subdividieron en sub parcelas de $20 \mathrm{~m}$ de ancho por 250 $\mathrm{m}$ de longitud y se enumeraron del 1 al 4, en el sentido de las agujas del reloj (Figura 3 y 4 ).

Figura 3. Unidad máxima de levantamiento de $1 \mathrm{Km}^{2}$ sub dividida en cuatro parcelas.

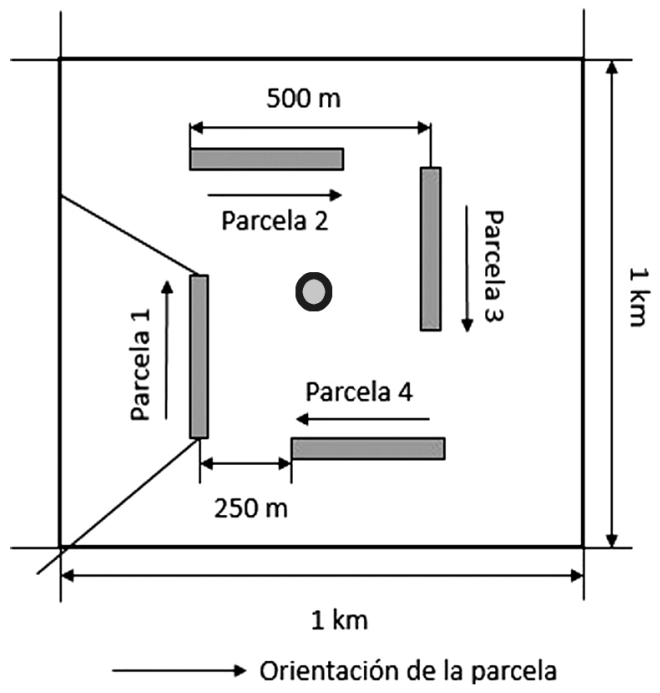

Fuente: Tomado de FAO (2004). 
Iván Sanabria-Coto, Instituto, Milagro Carvajal-Oses, Rooel Campos-Rodríguez, Paola Solera-Steller. Propuesta para una Delimitación Geográfica Integral del Manglar de Nosara, Guanacaste, Costa Rica

Figura 4. Mapa de las áreas de levantamiento fisiográfico propuestas dentro de la zona de estudio (polígono rojo).

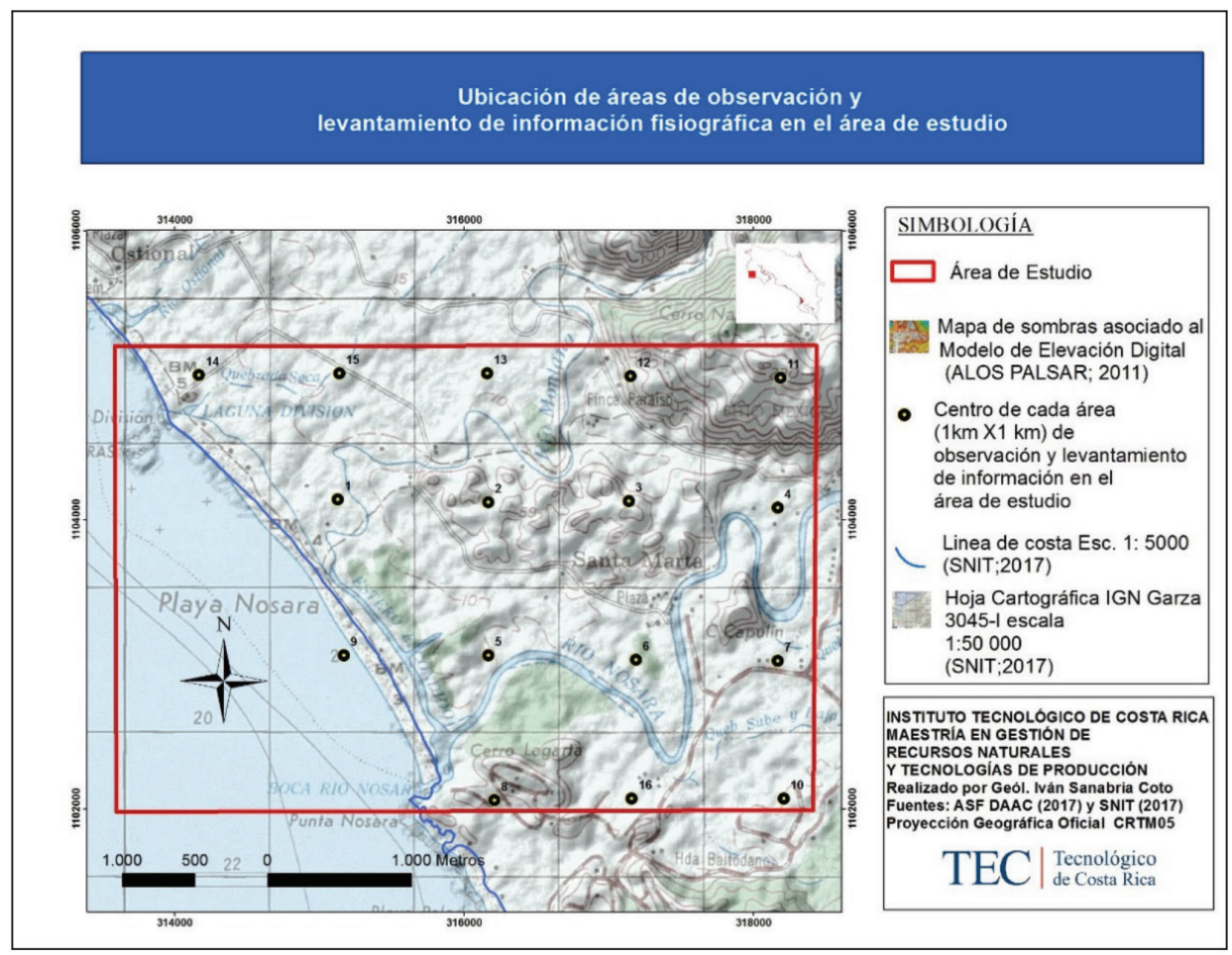


Iván Sanabria-Coto, Instituto, Milagro Carvajal-Oses, Rooel Campos-Rodríguez, Paola Solera-Steller. A Proposal for a Comprehensive Geographical Delimitation of the Mangrove of Nosara, Guanacaste, Costa Rica

Cuadro 1. Elementos fisiográficos analizados para la propuesta de delimitación del Manglar de Nosara.

\begin{tabular}{|c|c|}
\hline Elemento fisiográfico & Metodología \\
\hline Geología & $\begin{array}{l}\text { Se utilizó piqueta y ácido clorhídrico }(\mathrm{HCl}) \text { para toma de } \\
\text { macro-muestras, adicionalmente, se realizó un análisis } \\
\text { de características visuales como el color, peso (liviano, } \\
\text { normal o pesado), dureza (blando o duro), tamaño (fino, } \\
\text { mediano o compacto), orientación de componentes y } \\
\text { fracturas del terreno. }\end{array}$ \\
\hline Geomorfología & $\begin{array}{l}\text { Se realizó una caracterización visual del relieve en general } \\
\text { (formas de la corteza terrestre), el tipo de roca, el tamaño } \\
\text { de sedimento, la presencia o ausencia de fracturas o } \\
\text { pliegues. }\end{array}$ \\
\hline Sedimentación & $\begin{array}{l}\text { Se analizaron características visuales, de forma general, } \\
\text { como el tamaño del sedimento, forma (esfericidad, } \\
\text { planeidad), características superficiales (opacas, } \\
\text { traslúcidas, pulidas) y la orientación (paralelo, } \\
\text { perpendicular). }\end{array}$ \\
\hline Erosión & $\begin{array}{l}\text { En este apartado se utilizó la metodología de investigación } \\
\text { sobre uso de la tierra y dinámica erosión/sedimentación de } \\
\text { Hernández (2010a). }\end{array}$ \\
\hline Edafología & $\begin{array}{l}\text { Se aplicó la clave de bolsillo para determinar la capacidad } \\
\text { de uso de las tierras de Costa Rica de Cubero (2001). }\end{array}$ \\
\hline Hidrología & $\begin{array}{l}\text { Se utilizó como referencia la hoja cartográfica de Garza } \\
\text { 3045-I escala 1:50 } 000 \text { del IGN (SNIT, 2017). }\end{array}$ \\
\hline $\begin{array}{l}\text { Observación básica de } \\
\text { la vegetación }\end{array}$ & $\begin{array}{l}\text { Mediante una cámara fotográfica digital de marca Sony } \\
\text { se recolectaron las imágenes de las especies vegetales } \\
\text { de la zona y, posteriormente, se identifican utilizando la } \\
\text { información recabada por el Sistema Nacional de Áreas de } \\
\text { Conservación (2014). }\end{array}$ \\
\hline Relieve topográfico & $\begin{array}{l}\text { En este punto se empleó un clinómetro de la marca Suunto } \\
\text { para la estimación del ángulo con respecto a la pendiente } \\
\text { del relieve de la zona de estudio. }\end{array}$ \\
\hline $\begin{array}{l}\text { Identificación de áreas } \\
\text { de posible inundación }\end{array}$ & $\begin{array}{l}\text { Finalmente, para ello se utilizó como insumo los mapas de } \\
\text { la Comisión Nacional de Emergencia (CNE) (2016). }\end{array}$ \\
\hline
\end{tabular}

Fuente: Elaboración propia 
Iván Sanabria-Coto, Instituto, Milagro Carvajal-Oses, Rooel Campos-Rodríguez, Paola Solera-Steller. Propuesta para una Delimitación Geográfica Integral del Manglar de Nosara, Guanacaste, Costa Rica

\section{Análisis de la información}

Posterior a la investigación de campo y a la compilación de información sobre los elementos del contexto fisiográfico en el área de estudio, se procedió al análisis y procesamiento de los datos mediante SIG, utilizando el software Arcgis $10.3 \AA$.

La primera parte del proceso consistió en digitalización y georreferenciación del total de la información obtenida, utilizando el sistema oficial de coordenadas CRTM05 para la confección de los mapas. Complementariamente, se utilizaron insumos de percepción remota (Cuadro 2), tales como fotos aéreas, imágenes satelitales, Modelos de Elevación Digital (MEDs) y mapas de pendientes; suministradas por el Departamento de Servicios Digitalizados del Registro Nacional, el Instituto Tecnológico de Costa Rica (ITCR) y el CNE. Se accedieron a repositorios internacionales de la NASA, como el Alaska Satellite Facility (Servicio de Satélites de Alaska) para la obtención de capas de información geográfica en formato raster ligadas con MEDs, para la obtención de mapas de sombras y pendientes del relieve topográfico para el sitio de estudio. Por último, se utilizaron los formatos vectoriales de las capas compatibles en SIG y realizadas por Ortiz y Montoya (2014). Las fotografías impresas se analizaron por medio de un estereoscopio de la marca Sokkisha y se generaron de forma digital anáglifos para su uso con gafas polarizadas mediante el software libre Anagliph Marker 3D.

El mapa base utilizado incluyó los cambios espaciales históricos (1944-2016) vinculados con algunos de elementos fisiográficos detallados en el cuadro 1. Se utilizó una escala de trabajo de 1:15 000. 
Iván Sanabria-Coto, Instituto, Milagro Carvajal-Oses, Rooel Campos-Rodríguez, Paola Solera-Steller. A Proposal for a Comprehensive Geographical Delimitation of the Mangrove of Nosara, Guanacaste, Costa Rica

Cuadro 2. Insumos de percepción remota usados para el análisis con SIG.

\begin{tabular}{|c|c|c|}
\hline Imágenes Georreferenciadas & Escala & Origen \\
\hline CAW-11-111 a 113 & $1: 40000$ & Año 1944, Foto aérea del IGN. \\
\hline $\begin{array}{l}\text { VV-HURD-M7/AID } 61316- \\
1318 .\end{array}$ & $1: 30000$ & Año 1964, Foto aérea del IGN. \\
\hline Misión 16 Línea 6 448-451. & $1: 20000$ & Año 1971, Foto aérea del IGN. \\
\hline Misión 16 Línea 5 402-403. & $1: 20000$ & Año 1971, Foto aérea del IGN. \\
\hline $\begin{array}{l}22901 \text { R-169 Línea 220, } 125 \\
\text { y } 126 .\end{array}$ & $1: 40000$ & Año 1981, Foto aérea del IGN. \\
\hline $\begin{array}{l}\text { Imágenes Satelitales } \\
\text { I, Legacy Identifier } \\
\text { \#102001004B37DA00. }\end{array}$ & ------ & $\begin{array}{l}2016 \text { imagen de satélite, } \\
\text { adquiridas por el IGN a } \\
\text { empresa Digital Globe }{ }^{\circledR} \text {. }\end{array}$ \\
\hline Imágenes Satelitales II. & ------ & $\begin{array}{l}\text { Años 2004-2015 Imagen de } \\
\text { satélite gratuitas de Google } \\
\text { Earth }{ }^{\circledR} \text {. }\end{array}$ \\
\hline $\begin{array}{l}\text { Modelos de Elevación digital } \\
\text { (MED) \# ALPSRP272210180. }\end{array}$ & $\begin{array}{l}\text { Resolución de medio } \\
\text { segundo de arco. }\end{array}$ & $\begin{array}{l}\text { Año } 2011 \text { ALOS PALSAR de } \\
\text { Japan Aerospace Exploration } \\
\text { Agency and NASA disponible } \\
\text { en ASF DAAC (2017). }\end{array}$ \\
\hline $\begin{array}{l}\text { Mapa Digital de Zona Pública } \\
\text { de la ZMT de Costa Rica } \\
\text { (incluye manglares). }\end{array}$ & ---- & SNIT (2017) \\
\hline $\begin{array}{l}\text { Mapas de Tipo de Bosque del } \\
\text { MINAE } 2013 .\end{array}$ & ---- & $\begin{array}{l}\text { Centro Nacional de } \\
\text { Información Geoambiental } \\
\text { (CENIGA) (2017). }\end{array}$ \\
\hline
\end{tabular}

\section{Validación del área de delimitación propuesta para el Manglar de Nosara}

Para la escogencia de las áreas de muestreo se adoptó la metodología propuesta por Cintrón y Schaeffe (1984), la cual permite la conformación de transectos de banda que cubren la totalidad del área de interés. Cada transecto se sub dividió en parcelas (plots), con áreas mínimas de $100 \mathrm{~m}^{2}$ $(10 \mathrm{~m} \times 10 \mathrm{~m})$, las parcelas fueron trazadas paralelamente dentro de los ejes de los diferentes transectos. Se analizaron los elementos fisiográficos, anteriormente explicados metodológicamente (Cuadro 1) tanto dentro como fuera de la delimitación base del manglar por parte del IGN (Gaceta digital N. ${ }^{\circ} 20,2009$ ). Además, se realizaron muestras de suelos/sedimentos y agua. Cada una de las muestras de suelos y/o sedimentos tuvo un contenido de $500 \mathrm{~g} \mathrm{c} / \mathrm{u}$, usando una profundidad máxima de muestreo de $0-30 \mathrm{~cm}$ 
Iván Sanabria-Coto, Instituto, Milagro Carvajal-Oses, Rooel Campos-Rodríguez, Paola Solera-Steller.

Propuesta para una Delimitación Geográfica Integral del Manglar de Nosara, Guanacaste, Costa Rica

(Hernández; 2010a; Samper-Villarreal y Silva-Benavides, 2015; Barrantes y Cerdas, 2015). Las muestras fueron tomadas mediante palines y palas, se almacenaron en bolsas plásticas y seguidamente fueron etiquetadas para su envío al laboratorio. Se recolectó un total de 11 muestras para su respectivo análisis granulométrico y de nombre textural. En cuanto a las muestras de agua (para análisis de la conductividad eléctrica relacionada con su salinidad), se recolectó un total de cinco muestras provenientes de los sitios vinculados con condiciones hidrológicas representativas, tales como muestras intersticiales en el sedimento por perforación, en sedimentos saturados, cauces activos e intermitentes (secos). Las mismas fueron contenidas en recipientes plásticos esterilizados con un volumen de $300 \mathrm{ml}$.

\section{Resultados}

Se logró reconocer al menos tres especies propias de la distribución horizontal vegetal de los manglares en Costa Rica, definidas por Spotila, Marshall, Depew, Prince, Kennedy (2016) para el Pacifico Norte. Las especies identificadas correspondieron a mangle Rojo (Rhizophora mangle), Palo de sal (Avicennia germinans) y arbustos de Majagua (Hibiscus pernambucensis). Adicionalmente, durante el trabajo de campo se comprobó, en algunas parcelas, la existencia de la respectiva delimitación física en concreto (amojonamientos). El siguiente cuadro resume el restante de los elementos fisiográficos hallados en la zona de estudio. 
Iván Sanabria-Coto, Instituto, Milagro Carvajal-Oses, Rooel Campos-Rodríguez, Paola Solera-Steller. A Proposal for a Comprehensive Geographical Delimitation of the Mangrove of Nosara, Guanacaste, Costa Rica

Cuadro 3. Integración de la información fisiográfica.

\begin{tabular}{|c|c|}
\hline $\begin{array}{l}\text { Elementos fisiográficos } \\
\text { investigados }\end{array}$ & $\begin{array}{l}\text { Resumen de la información obtenida en el } \\
\text { reconocimiento de campo }\end{array}$ \\
\hline Geología & $\begin{array}{l}85 \% \text { de las muestras analizadas in situ correspondieron a } \\
\text { sedimentos y } 15 \% \text { a rocas de origen sedimentario. }\end{array}$ \\
\hline Geomorfología & $\begin{array}{l}70 \% \text { de los elementos geomorfológicos estuvieron asociados } \\
\text { a condiciones fluviales. }\end{array}$ \\
\hline Tectónica & $\begin{array}{l}\text { Se observaron evidencias que respaldan la influencia } \\
\text { tectónica activa, especialmente, del Graben de Nosara, como } \\
\text { parte de la modelación del relieve topográfico existente. } \\
\text { Posee una constante deformación tectónica caracterizada por } \\
\text { levantamientos costeros de índole cosísmica. }\end{array}$ \\
\hline Erosión/sedimentación & $\begin{array}{l}\text { Se apreciaron fuertes indicios de erosión fluvial lateral, } \\
\text { especialmente, en la parte de los meandros del Río Nosara, } \\
\text { así como las respectivas acumulaciones de sedimentos en } \\
\text { zonas de baja energía. }\end{array}$ \\
\hline $\begin{array}{l}\text { Características } \\
\text { edafológicas }\end{array}$ & $\begin{array}{l}\text { El } 60 \% \text { de las características granulométricas correspondían } \\
\text { a texturas finas y moderadamente finas, el restante } \\
\text { porcentaje de medianas a gruesas. }\end{array}$ \\
\hline Hidrología & $\begin{array}{l}\text { Se identifican al menos cinco cauces de agua con flujo } \\
\text { activo ligados con los siguientes elementos hidrológicos: } 1 . \\
\text { Río Nosara, 2. Río Montaña, 3. Quebrada Seca, } 4 \text {. Estero } \\
\text { Escondido y 5. Quebrada Sube y Baja, así como de al menos } \\
\text { nueve cauces ocasionales en el área de estudio. Además, } \\
\text { según el registro de pozos del Servicio Nacional de Aguas } \\
\text { Subterráneas Riego y Avenamiento (SENARA) (2016) hay } \\
\text { presencia de niveles freáticos muy someros conforme hay un } \\
\text { acercamiento a la línea de costa (de } 0,16 \text { a } 4 \mathrm{~m} \text { ). }\end{array}$ \\
\hline Relieve topográfico & $\begin{array}{l}\text { Los análisis de la pendiente en función del relieve mostraron } \\
\text { más del } 60 \% \text { del área con relieves planos a ligeramente } \\
\text { ondulados }\left(0^{\circ}-20^{\circ}\right) \text {. }\end{array}$ \\
\hline $\begin{array}{l}\text { Áreas de potencial } \\
\text { inundación }\end{array}$ & $\begin{array}{l}\text { Las principales áreas de inundación correspondieron a } \\
\text { sectores de bajo relieve topográfico en zonas aledañas a los } \\
\text { ríos y con gradientes que oscilan entre } 0^{\circ}-10^{\circ} \text {. }\end{array}$ \\
\hline
\end{tabular}

La información obtenida de cada elemento fisiográfico se integró mediante SIG, logrando identificar y delimitar un sector o polígono geográfico determinado que integró las condiciones más óptimas para el emplazamiento del Manglar Nosara (Figura 5), la cual cubrió la totalidad de amojonamientos de la Zona Pública (ZMT) realizados por el IGN e incluyó así mismo los sectores con la distribución de especies de manglar determinado por el SINAC (2014). 
Iván Sanabria-Coto, Instituto, Milagro Carvajal-Oses, Rooel Campos-Rodríguez, Paola Solera-Steller. Propuesta para una Delimitación Geográfica Integral del Manglar de Nosara, Guanacaste, Costa Rica

Figura 5. Propuesta para una delimitación geográfica del manglar de Nosara.

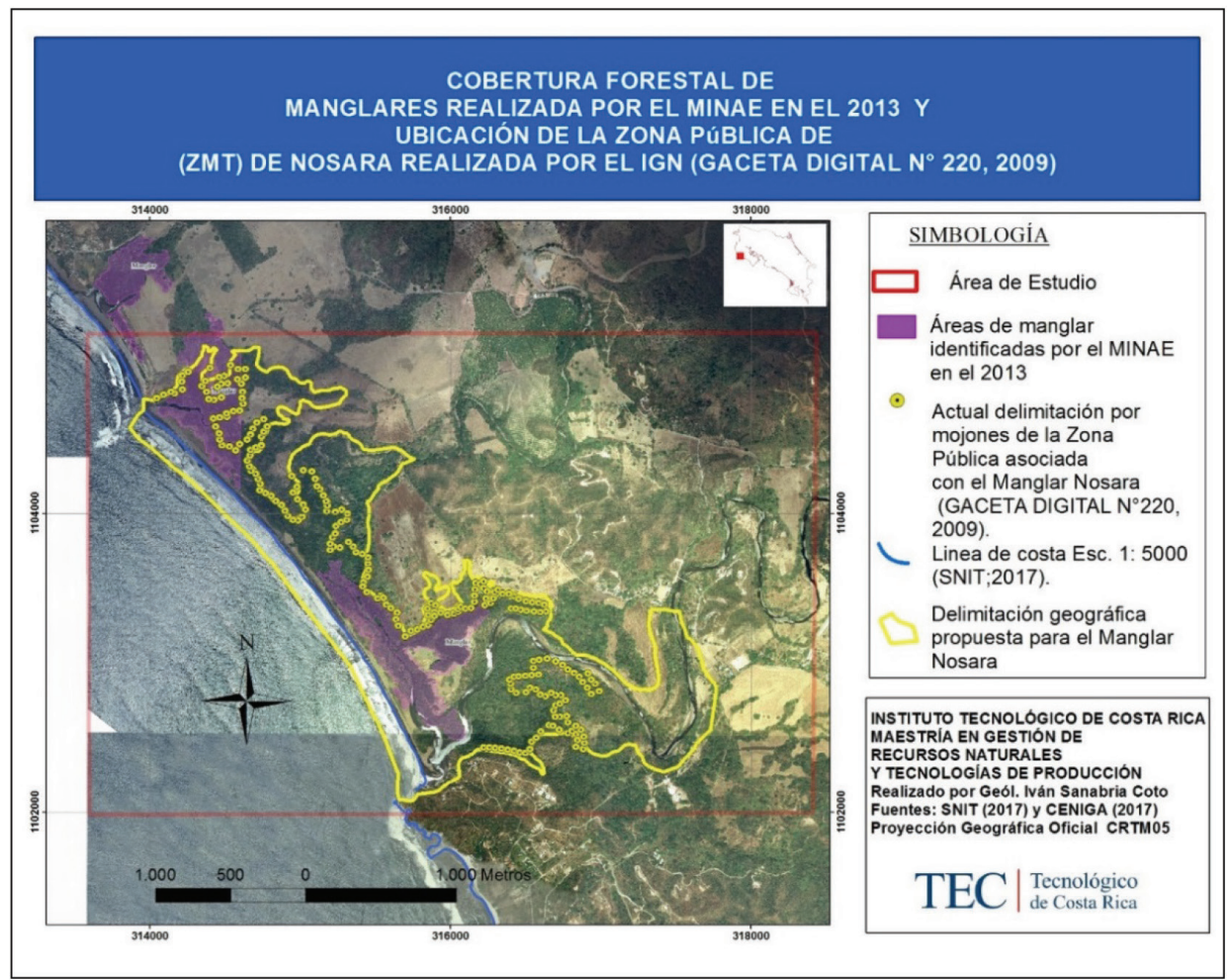

Cabe recalcar que el criterio fundamental para la delimitación de la propuesta radicó en la reconstrucción de las principales evidencias geomorfológicas, las cuales son producto de la sinergia entre los procesos y condiciones vinculadas con el área del manglar. Por tanto, los cambios en la dinámica fluvio/costera determinan las modificaciones espaciales en estos ecosistemas (Woodroffe et al., 2016), en la figura 6, se muestran las morfologías asociadas con cauces activos, ocasionales, meandros abandonados y terrazas fluviales en el área de estudio (desde año 1946-2016). Así mismo, se pueden observar extensas áreas con aportes superficiales de aguas continentales de ríos y quebradas. 
Iván Sanabria-Coto, Instituto, Milagro Carvajal-Oses, Rooel Campos-Rodríguez, Paola Solera-Steller. A Proposal for a Comprehensive Geographical Delimitation of the Mangrove of Nosara, Guanacaste, Costa Rica

Figura 6. Mapa de reconstrucción geomorfológica para el Manglar Nosara.

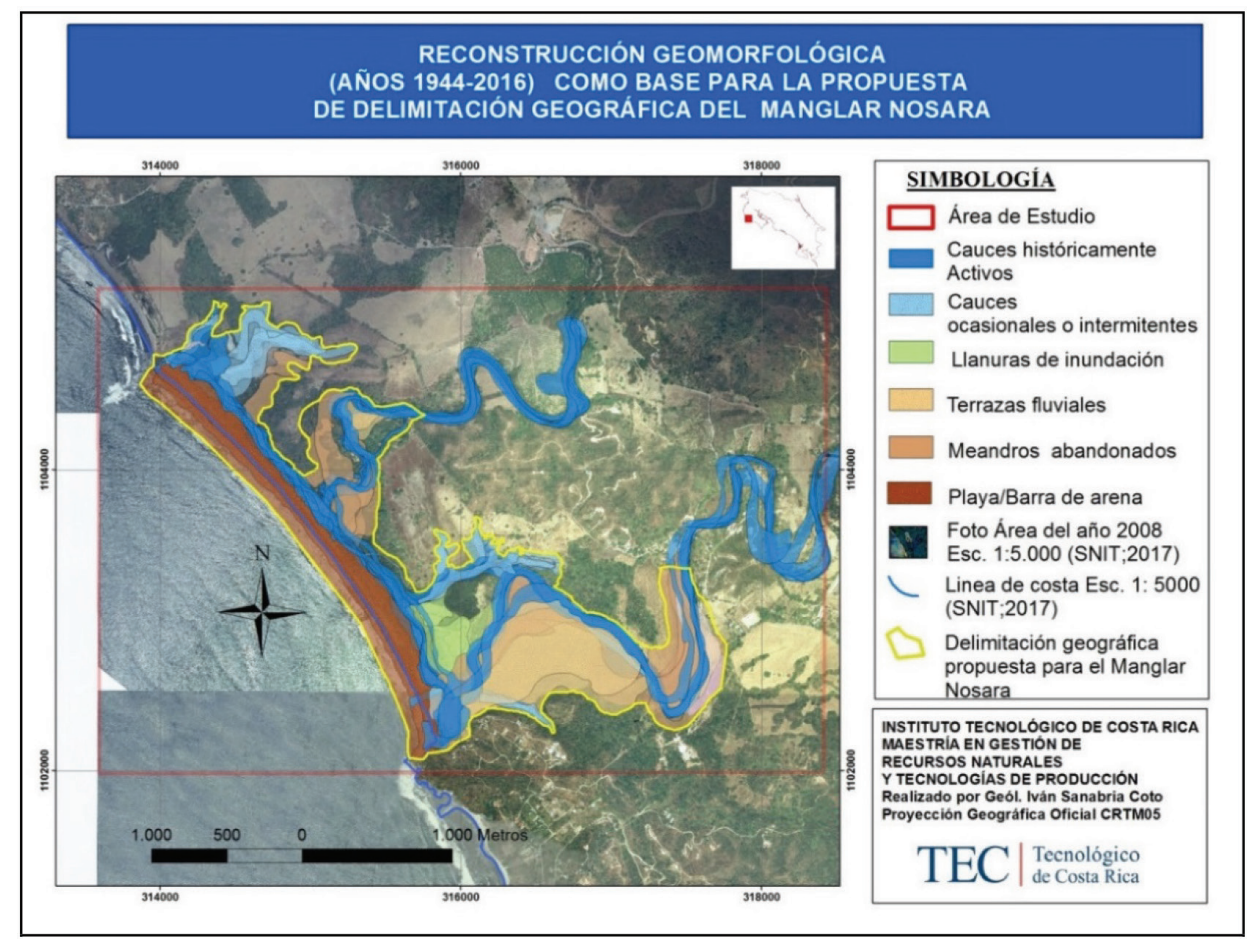

Durante la validación de la propuesta, la mayor parte del área de delimitación (>95\%) estuvo asociada con bajos relieves topográficos, patrones hidrográficos con evidentes cambios laterales y con sedimentos no consolidados; además de vegetación de manglar asociada (mangle rojo, mangle negro y arbustos de majagua).

Según la clasificación de los manglares, de acuerdo con la geomorfología regional de Yáñez, Twilley, Lara (1998), en Nosara se identificaron manglares de tipo estuarino y de laguna; y a nivel ecológico, de al menos tres tipos fisiográficos: de borde, ribereño y de cuenca; los cuales mantienen una relación con la zonación existente.

Conforme se avanzó en los transectos, desde la sección externa de la costa a lo interno del continente se observaron cambios texturales macroscópicos en suelos/sedimentos para las muestras recolectadas; producto de la gradación de sedimentos por el aporte marino, cerca de la costa se presentó preponderancia de grano grueso (arenas), mientras que a lo 
Iván Sanabria-Coto, Instituto, Milagro Carvajal-Oses, Rooel Campos-Rodríguez, Paola Solera-Steller. Propuesta para una Delimitación Geográfica Integral del Manglar de Nosara, Guanacaste, Costa Rica

interno del continente, debido al aporte fluvial de la zona continental, se observaron facies de sedimentos con predominancia de grano más fino, caracterizado por texturas de limos y arcillas.

En la figura 7, se muestran los perfiles texturales de suelos, numerados del uno al seis, los cuales están caracterizados, mayoritariamente por sedimentos con texturas de tipo arenosas a arenosas francosas, siendo propios de la parte costera (influencia de mareas) y en menor medida arcillosos, los cuales guardan relación con especies vegetales como Avicennia germinans y Rhizophora mangle. Además, se apreció la predominancia de suelos de tipo Inceptisoles (mayoritariamente) y Alfisoles.

Figura 7. Mapa de nombres texturales (de laboratorio) para muestras de suelos/sedimentos.

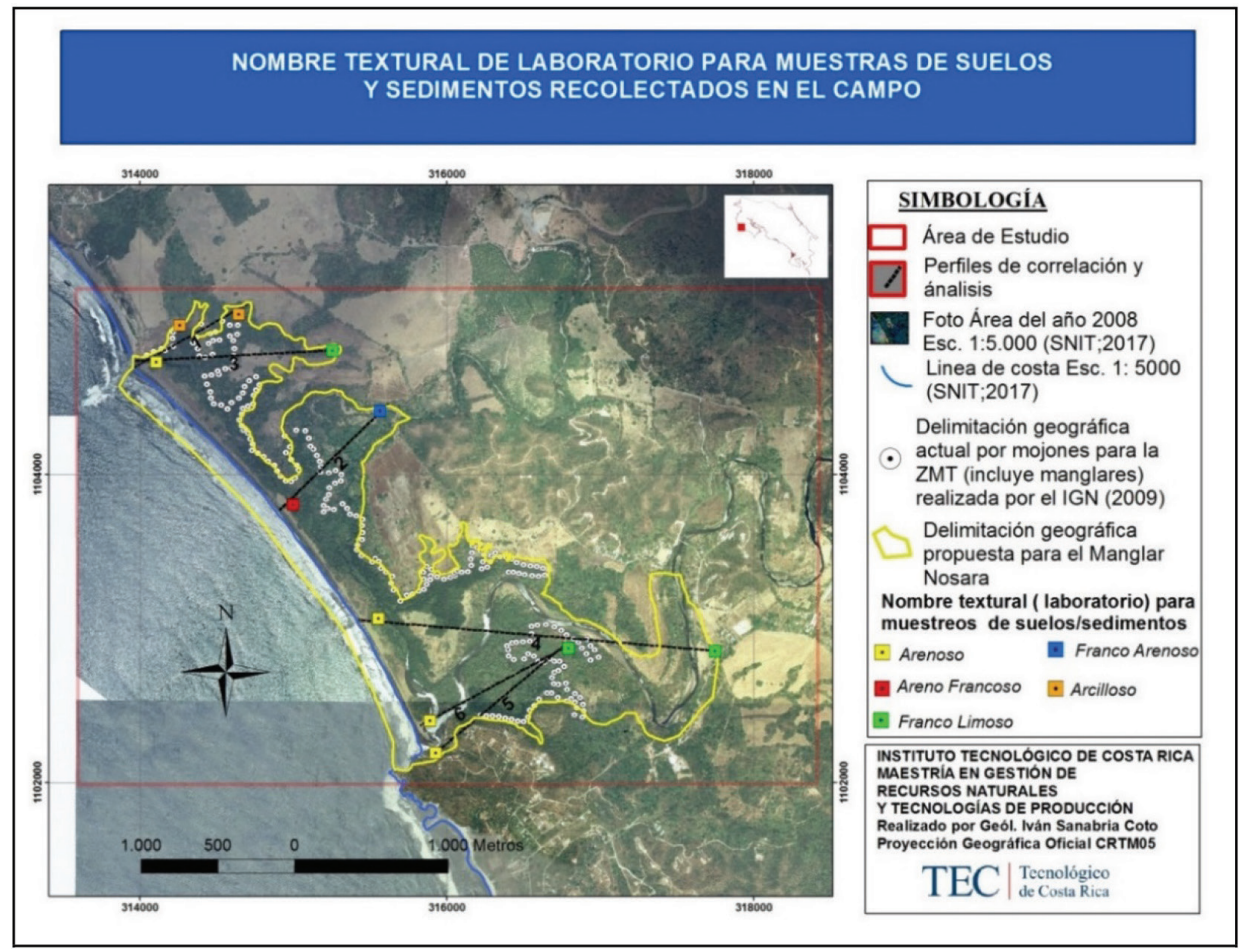


Iván Sanabria-Coto, Instituto, Milagro Carvajal-Oses, Rooel Campos-Rodríguez, Paola Solera-Steller. A Proposal for a Comprehensive Geographical Delimitation of the Mangrove of Nosara, Guanacaste, Costa Rica

Las mayores conductividades eléctricas correspondieron a $52,9 \mathrm{mS} / \mathrm{cm}$ para las muestras más cercanas a la costa y $0,33 \mathrm{mS} / \mathrm{cm}$ para las muestras de agua tomadas hacia el continente, esto asociado con un aporte marino que sufre dilución superficial por aguas continentales tierra adentro (Figura 8).

Figura 8. Mapa de conductividades eléctricas para muestras de agua recolectadas.

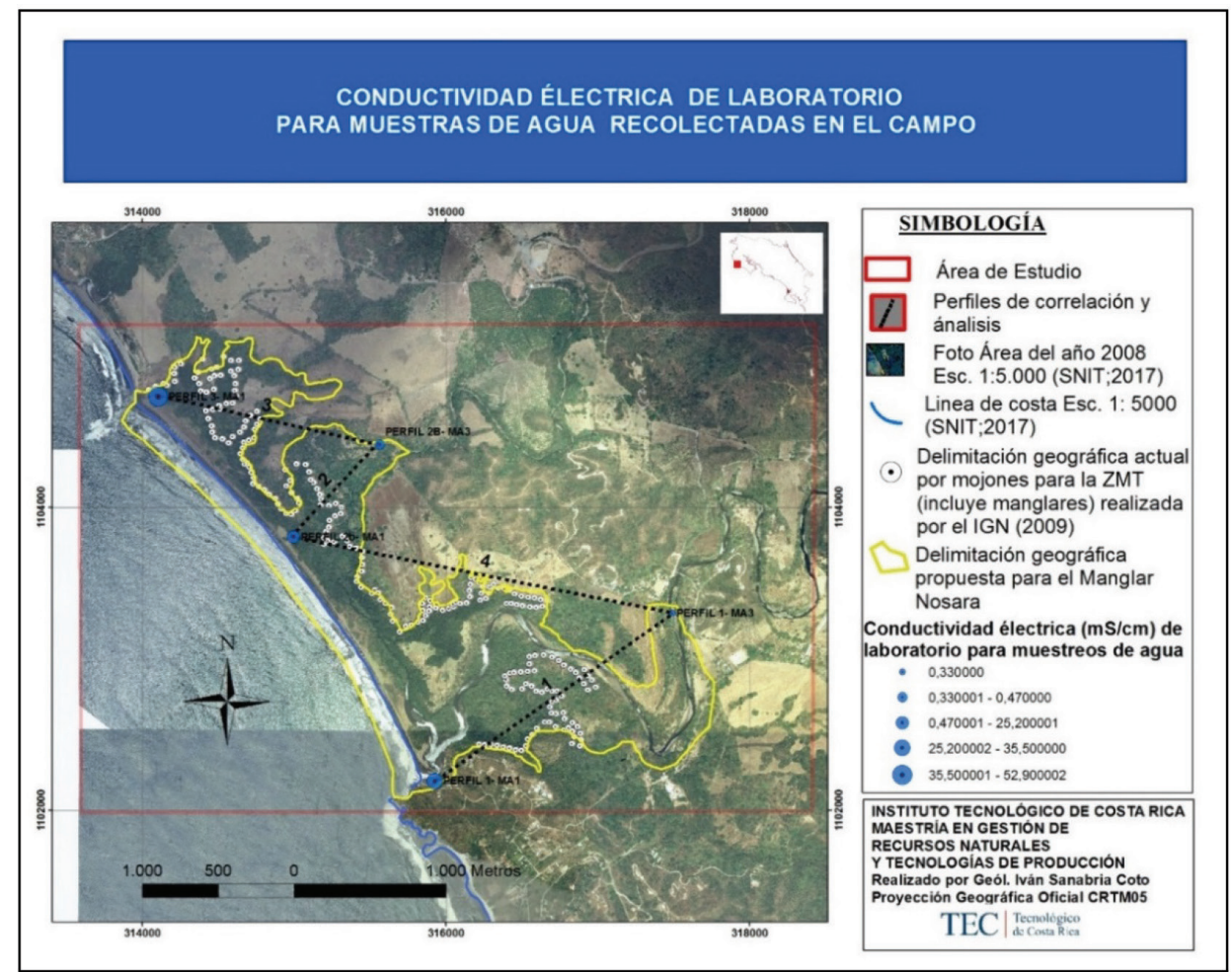

Finalmente, los suelos/sedimentos muestreados y sus porcentajes granulométricos asociados se correlacionaron con la sedimentación observada producto de cauces ocasionales o intermitentes, así como amplias zonas de inundación identificada, zonas de bajo relieve topográfico y con elementos hidrográficos asociados con el Río Nosara y la Quebrada Montaña (Figura 9). 
Iván Sanabria-Coto, Instituto, Milagro Carvajal-Oses, Rooel Campos-Rodríguez, Paola Solera-Steller. Propuesta para una Delimitación Geográfica Integral del Manglar de Nosara, Guanacaste, Costa Rica

Figura 9. Correlación entre porcentajes texturales del suelo y la sedimentación.

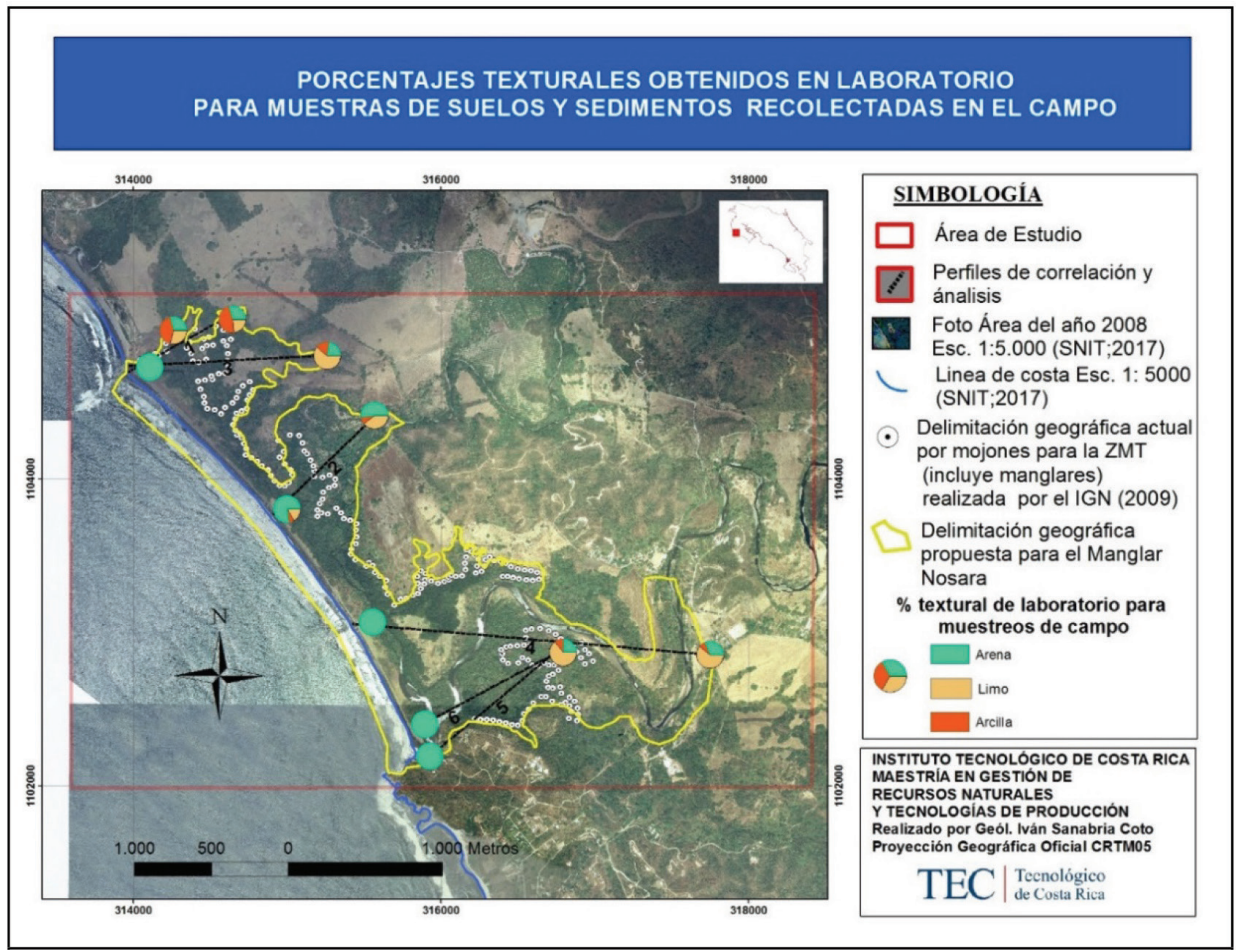

\section{Discusión de resultados}

El conocimiento fisiográfico de una región implica, además de la identificación de los principales rasgos del relieve, la explicación de los procesos que intervinieron en su modelado y que le han dado su aspecto actual; desde su origen, esto ha sido reconocido y empleado en países como Colombia, para la clasificación y caracterización de unidades de tierras como primera aproximación al conocimiento de las relaciones que se desarrollan en el espacio geográfico y en el biofísico (Serrato, 2009).

Según Woodroffe et al. (2016) existe una clara relación entre las zonas costeras geomorfológicamente activas y las especies de manglar presentes, por lo tanto, los cambios geomorfológicos en el contexto del manglar Nosara; los cuales han incluido tanto variaciones en la línea de costa actual, debido a efectos en la regresión y transgresión marina, como cambios en la dinámica del Río Nosara por modificación meándrica, han 
Iván Sanabria-Coto, Instituto, Milagro Carvajal-Oses, Rooel Campos-Rodríguez, Paola Solera-Steller. A Proposal for a Comprehensive Geographical Delimitation of the Mangrove of Nosara, Guanacaste, Costa Rica

influido directamente en la distribución geográfica vegetal del manglar (Figura 10).

Figura 10. Fotos e imágenes aéreas históricas que muestran las variaciones geomorfológicas en el área de estudio (SNIT, 2017).

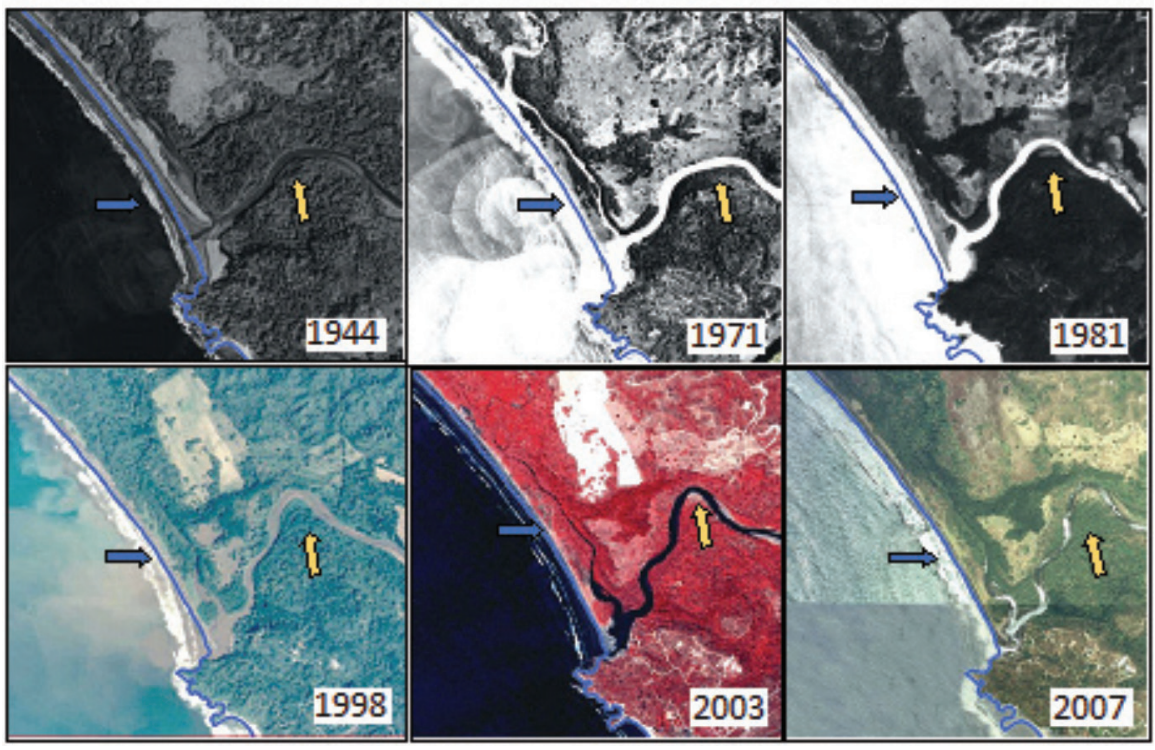

Además, en el Manglar Nosara se han desarrollado sectores geológicamente favorables para la acumulación de sedimentos (materiales inconsolidados); no obstante, debido a la profundidad del basamento consolidado y a los contactos laterales rocosos, se podría condicionar o restringir la adaptación de diferentes especies de manglar al sustrato (Denyer et al., 2004).

El área asociada con este manglar posee una constante deformación tectónica caracterizada por levantamientos costeros regionales, además de estructuras tectónicas asociadas con fallas activas, que por su tipo de deformación reciente provocan cambios evidentes en el terreno (Denyer et al., 2009; Denyer et al., 2014; Montero y Denyer, 2014). La existencia de estas estructuras tectónicas incide directamente en posibles alteraciones en la dinámica del factor hidrológico; siendo este último un aspecto fisiográfico fundamental para el establecimiento y permanencia de la distribución de especies vegetales. 
Iván Sanabria-Coto, Instituto, Milagro Carvajal-Oses, Rooel Campos-Rodríguez, Paola Solera-Steller. Propuesta para una Delimitación Geográfica Integral del Manglar de Nosara, Guanacaste, Costa Rica

Así mismo, el área de estudio al poseer niveles de agua subterránea que se somerizan conforme se aproxima a la costa hace suponer la posible existencia de áreas de manglar con un posible desarrollo "freatofito", asociado con el aporte de aguas subterráneas en sus raíces, la Clasificación y Conservación de Humedales en Costa Rica (2010) indica que la interacción interna del agua en el suelo facilita la saturación hídrica en suelos asociados con humedales, lo cual está relacionado con el emplazamiento de los manglares (Zaldívar, Herrera, Teutli, Hernández, Caamalsosa, 2010). Sumado a lo anterior, hay presencia de zonas inundables que potencia también el aumento de la condición hídrica de los suelos saturados; donde la frecuencia, duración de la inundación y saturación del suelo varía en forma amplia de permanentemente saturado a irregularmente inundado (Hernández, 2010b; Clasificación y Conservación de Humedales, 2010; $\mathrm{CNE}, 2016)$. La influencia del agua continental propicia variaciones en la salinidad y se han reportado en áreas aledañas a Nosara salinidades entre 5 y 35 ppt (Brenes, Márquez, Quirós, 2012; SINAC, 2014).

Además, se observó la predominancia de dos clases de suelos clasificados como Inceptisoles y Alfisoles, lo cual concuerda con los resultados obtenidos por otros autores como Hernández (2010 b) o por Ortiz y Montoya (2014), según el Ministerio de Agricultura y Ganadería (2017), el primer tipo de suelo está asociado a condiciones ligeramente planas o totalmente planas y a sedimentos fluviales.

En cuanto a la erosión fluvial lateral hallada en la zona, lo observado concuerda por lo investigado por Hernández (2010b) en su Modelo de Erosión/Sedimentación (MES) para los años 2004-2006; específicamente, para la parte baja de la Cuenca del Río Nosara.

Cabe resaltar, que el Rizophora mangle y Avicennia germinans son especies caracterizadas por ser colonizadoras de las zonas intermareales (Delgado et al., 2001), en el caso específico de A. germinans, al producir pequeños propágulos su posibilidad de dispersión aumenta (Jiménez, 1994), y más si el terreno posee características planas e inundables como en Nosara. Según Cogni, Freitas, Oliveira (2003) Hibiscus pernambucensis puede colonizar ambientes distintos, ya sea en bosques arenosos permanentemente secos o en bosques inundados.

A pesar de que la actual delimitación amojonada por parte del IGN (Gaceta Digital No 20,2009) incluye parte esencial del manglar, en la actual 
Iván Sanabria-Coto, Instituto, Milagro Carvajal-Oses, Rooel Campos-Rodríguez, Paola Solera-Steller. A Proposal for a Comprehensive Geographical Delimitation of the Mangrove of Nosara, Guanacaste, Costa Rica

investigación se demostró que existen potenciales condiciones fisiográficas para la expansión en la distribución horizontal de especies de mangle en Nosara ; entre las que se puede mencionar cambios del nivel del mar, variaciones en la geomorfología de la costa, fenómenos asociados con el clima, aporte de sedimentos terrígenos hacia la costa y suficiente aporte de agua dulce. Sumado a lo anterior, para Costa Rica existe posibilidad de un aumento en el nivel del mar, con un escenario realista de ascenso de un metro de altura o más para el año 2100, lo que hace prever que los tipos de costa caracterizados, preferentemente, por playas en el frente de llanuras aluviales y marismas (como el área de estudio) serán las más vulnerables; conllevando consecuentes transgresiones de la línea ribereña actual y ampliación de las áreas sujetas a inundación mareal (Valverde et al., 2016).

Por lo tanto, es necesario conformar una zona de amortiguamiento (ZA) (Figura 11) que se sume a la actual delimitación oficial del Manglar Nosara, que pueda ser incluida dentro de los planes maestros costeros del uso de suelo en la ZMT. Cabe resaltar que el concepto de ZA para los manglares de Costa Rica no es nuevo, pues ha sido también mencionado por Benavides et al. (2016) para varios manglares de Bahía Culebra y Guanacaste, donde estos autores manifiestan que es conveniente que la protección de los manglares también incluya la protección de áreas de su alrededor, lo cual permitiría reducir impactos futuros. 
Iván Sanabria-Coto, Instituto, Milagro Carvajal-Oses, Rooel Campos-Rodríguez, Paola Solera-Steller. Propuesta para una Delimitación Geográfica Integral del Manglar de Nosara, Guanacaste, Costa Rica

Figura 11. Propuesta final para una delimitación integral del Manglar de Nosara.

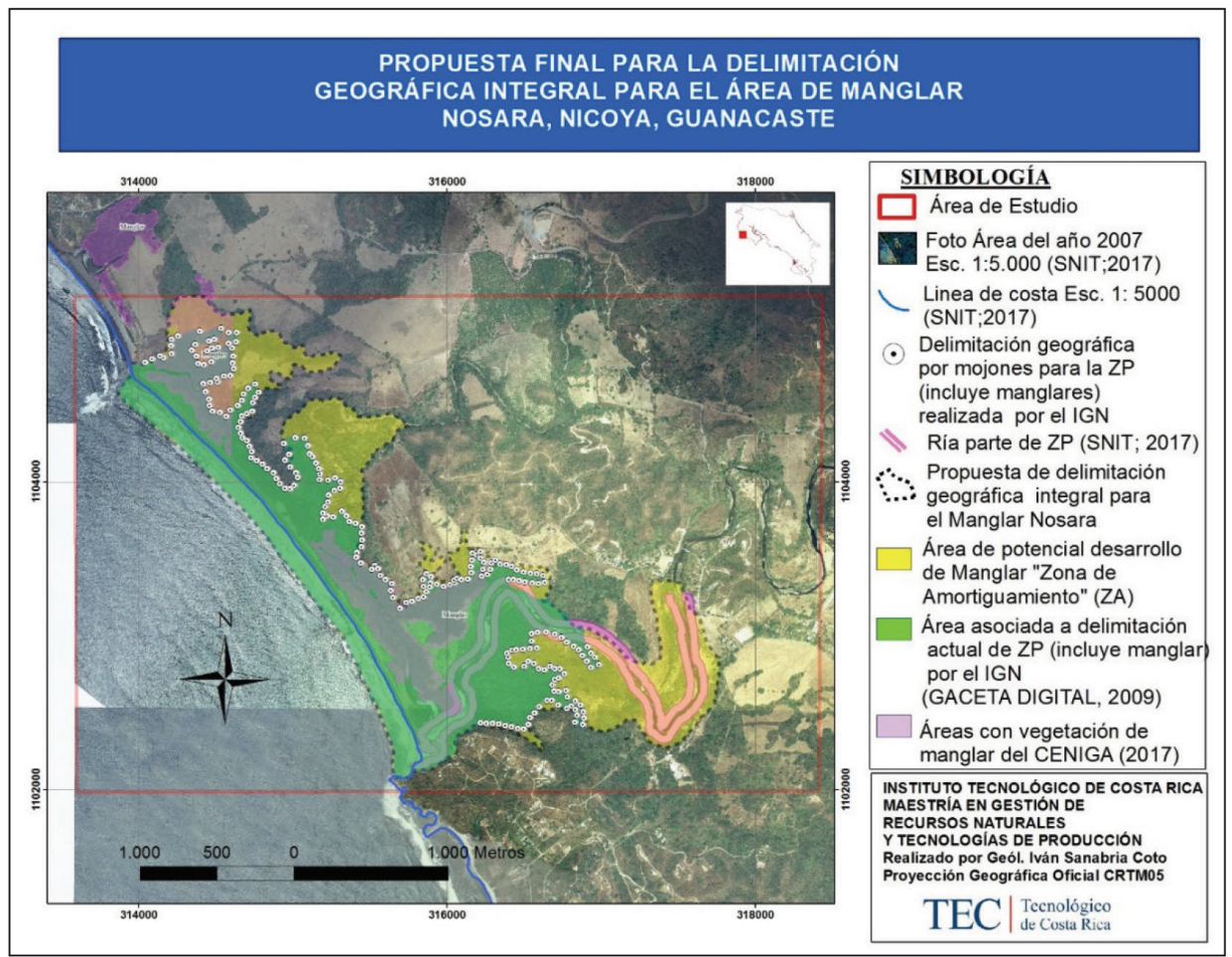

En vista de que las áreas que formarían parte de la ZA del Manglar Nosara podrían estar asociadas con propiedad privada, las regulaciones deben estar enfocadas a la implementación de actividades que guarden estrecha relación con los servicios ecosistémicos compatibles con la conservación de los suelos y la no construcción de infraestructura, que eventualmente dificulte o estrangule la futura adaptación vegetal del manglar; entre los cuales, el artículo 45 de la Ley Orgánica del Ambiente No 7554 (1995) señala diques, drenajes, rellenos o desecamientos; ante cambios en la geodinámica del área por el aumento del nivel del mar, de orden climático, tectónico, entre otros, del área (Instituto Geofísico de Perú, 2013; SINAC, 2014). Sumado a lo anterior, la Ley Orgánica del Ambiente (1995) señala también que los terrenos adyacentes a humedales deben estar sujetos a limitaciones y restricciones de uso para conservación y uso sostenible del suelo. 
Iván Sanabria-Coto, Instituto, Milagro Carvajal-Oses, Rooel Campos-Rodríguez, Paola Solera-Steller. A Proposal for a Comprehensive Geographical Delimitation of the Mangrove of Nosara, Guanacaste, Costa Rica

Adicionalmente, tanto la identificación de actores claves como de las actividades productivas asociadas corresponden al primer paso para propiciar propuestas de uso sostenible de los servicios ecosistémicos, siendo el factor social relevante en el proceso. Según la Fundación Neotrópica (2013), la sensibilización de la población sobre el tema es el primer paso para recuperar las superficies de manglares, donde primero es importante frenar la pérdida de los manglares por causas antrópicas.

\section{Referencias}

ASF DAAC (2017). Modelo de Elevación Digital (AP_27221_FBS_ F0180_RT1). Recuperado de https://vertex.daac.asf.alaska.edu/.

Barrantes, M., Cerdas, A. (2015). Distribución espacial de las especies de mangle y su asociación con los tipos de sedimentos del sustrato, en el sector estuarino del Humedal Nacional Térraba-Sierpe, Costa Rica. En: Revista de Biología Tropical, 63, 47-60.

Benavides-Varela, C., Samper-Villarreal, J., Cortés, J. (2016). Cambios en la cobertura de manglares en Bahía Culebra, Pacífico Norte de Costa Rica (1945-2010). En: Revista de Biología Tropical, 64(3), 955-964. Berger, U., Rivera-Monroy, V., Doyle, T., Dahdouh-Guebas, F., Duke, N., Fontalvo-Herazo, M., Hildenbrandt, H., Koedam, N., Mehlig, M., Piou, C., Twilley, R. (2008). Advances and limitations of individual-based models to analyze and predict dynamics of mangrove forests: A review. En: Aquatic Botany, 89, 260-274.

Brenes, C., Márquez, A., Quirós, W. (2012). Rasgos Hidrográficos y Batimétricos del Refugio Nacional de Vida Silvestre Ostional y Áreas Adyacentes, Guanacaste, Costa Rica. En: Revista Marino Costero, 4, 145-156.

CENIGA (Centro Nacional de Información Geoambiental). (2017). Mapa de tipos de bosque 2013. Sistema Nacional de Áreas de Conservación (SINAC) del Ministerio de Ambiente y Energía (MINAE). Recuperado de http://ceniga.sinac.go.cr/geonetwork/ srv/eng/main.home.

Cintrón, G. \& Schaeffe, Y. (1984). Methods for studying mangrove. en Snedaker (91-113),E. C., y J. G. Snedaker [Eds.]. The mangrove ecosystem: Research methods. Monogr. Oceanogr. Methodol. Estados Unidos y Francia: UNESCO. 
Iván Sanabria-Coto, Instituto, Milagro Carvajal-Oses, Rooel Campos-Rodríguez, Paola Solera-Steller.

Propuesta para una Delimitación Geográfica Integral del Manglar de Nosara, Guanacaste, Costa Rica

Clasificación y Conservación de Humedales. (2010). Publicado en la GACETA N $^{\circ}$ 73, del 16 de abril de 2010. Costa Rica.

Comisión Nacional de Emergencias (CNE). (2016). Mapas de amenazas naturales para Costa Rica. Recuperado de https://www. cne.go.cr/index.php/prevencie-desastres-menuprincipal-93/ mapas-de-amenazas.

Cogni, R., Freitas, A., Oliveira, P. (2003). Interhabitat differences in ant activity on plant foliage: ants at extrafloral nectaries of Hibiscus pernambucensis in sandy and mangrove forests. En: Entomologia Experimentalis et Applicata, 107(2), 125-131.

Costanza, R. \& Folke, C. (1997). Valuing Ecosystem Services with Efficiency, Fairness and Sustainability as Goals. Estados Unidos: Island Press.

Cubero, D. (2001). Clave de bolsillo para determinar la capacidad de uso de las tierras de Costa Rica. Ministerio de Agricultura y Ganadería Dirección de Planificación del Uso de la Tierra. San José Costa Rica: Editorial Asociación Costarricense de la Ciencia del Suelo.

Decreto No 36642-MP-MOPT-MINAET. (2011). Reglamento de Especificaciones para la Delimitación de la Zona Pública de la Zona Marítimo terrestre Publicado en la Gaceta No 136, del 14 de julio de 2011. Costa Rica.

Decreto No 36786-MINAET. (2011). Manual para la clasificación de tierras dedicadas a la conservación de los recursos naturales dentro de la Zona Marítimo Terrestre en Costa Rica. Publicado en la Gaceta $\mathrm{N}^{\mathrm{o}} 217$, del 11 de noviembre de 2011. Costa Rica.

Decreto No 35803-MINAET. (2010). Criterios técnicos para la identificación, Clasificación y conservación de humedales. Publicado en la GACETA No 73, del 16 de abril de 2010. Costa Rica.

Delgado, P., Hansel, P., Jiménez, J. \& Day, J. (2001). The importance of propagule establishment and physical factors in mangrove distributional patterns in a Costa Rican estuary. En: Aquatic Botany, 71. 157-178.

Denyer, P., Aguilar, T. \& Montero, W. (2014). Cartografía geológica de la península de Nicoya, Costa Rica, estratigrafía y tectónica. Costa Rica: Editorial de la Universidad de Costa Rica. 
Iván Sanabria-Coto, Instituto, Milagro Carvajal-Oses, Rooel Campos-Rodríguez, Paola Solera-Steller. A Proposal for a Comprehensive Geographical Delimitation of the Mangrove of Nosara, Guanacaste, Costa Rica

Denyer, P., Montero, W. \& Alvarado, G. (2009). Atlas tectónico de Costa Rica (2da ed.). Ed. Univ. Costa Rica: Costa Rica. (p.55).

Food and Agriculture Organization (FAO). (2004). Inventario Forestal Nacional Modelo de Manual de Campo. Documento de trabajo ERF. $94 \mathrm{E} / \mathrm{F} / \mathrm{S}$. Roma.

Fundación Neotrópica. (2013). El manglar, un ecosistema para conservar: manual de reforestación. Recuperado de http://neotropica.org/wpcontent/uploads/2012/08/Manual-de-Reforestacion-Manglar.pdf. Revisado el 1 de febrero del 2018.

Gaceta Digital No 220. (29 de enero, 2009). Instituto Geográfico Nacional Departamento de Geodesia y Topografía. Aviso N. ${ }^{\circ}$ 2009-16 Zona Marítimo Terrestre: Amojonamiento de Zona Pública entre sectores de Playa Ostional hasta Playa Guiones. La Gaceta Digital Diario Oficial de Costa Rica. Imprenta Nacional de Costa Rica.

Giri, C., Ochieng, E., Tieszen, L., Zhu, Z., Singh, A., Loveland, T., Masek, J., Duke, N. (2010). Status and distribution of mangrove forests of the world using earth observation satellite data. En: Global Ecology and Biogeography, 20, 154-159.

Held, A., Ticehurst, C., Lymburner, L. \& Williams, N. (2010). High resolution mapping of tropical mangrove ecosystems using hyperspectral and radar remote sensing. En: International Journal of Remote Sensing, 24(13), 2739-2759.

Hernández, A. (2010 a). Formaciones superficiales y procesos morfodinámicos en la cuenca del Río Nosara. En: Revista Reflexiones, 89(2), 39-49.

Hernández, A. (2010 b). Desarrollo Geomorfología, uso de la tierra y dinámica erosión/sedimentación como aspectos claves para iniciar la gestión ambiental en la cuenca hidrográfica del rio Nosara, Guanacaste, Costa Rica. (Tesis sometida a la consideración del Programa de Estudios del Doctorado en Ciencias Naturales para el Desarrollo, para optar por el Grado de Doctor Académico UNED-ITCR-UNA). Instituto de Geofísica del Perú. (2013). Identificación de servicios ecosistémicos en el Santuario Nacional los Manglares de Tumbes. Informe especial Técnico Recuperado de http://repositorio.igp.gob.pe/handle/IGP/477. Revisado el 1 de febrero del 2018. 
Iván Sanabria-Coto, Instituto, Milagro Carvajal-Oses, Rooel Campos-Rodríguez, Paola Solera-Steller. Propuesta para una Delimitación Geográfica Integral del Manglar de Nosara, Guanacaste, Costa Rica

Jiménez, J.A. (1994). Los manglares del Pacífico Centroamericano. Editorial Fundación UNA, Heredia, Costa Rica

Lee, T. \& Yeh, H. (2009). Applying remote sensing techniques to monitor shifting wetland vegetation: A case study of Danshui River estuary mangrove communities, Taiwan. En: Ecological engineering, 35(4), 487-496.

Ley $N^{o}$ 7554. (1995). Ley Orgánica del Ambiente. (1995). Publicada en el Diario Oficial La Gaceta $\mathrm{N}^{\circ} 215$, del 13 de noviembre de 1995. Costa Rica.

Ley $N^{o}$ 6043. (1977). Ley de Zona Marítima Terrestre. Publicada en el Diario Oficial La Gaceta No 52, del 16 de marzo de 1977. Costa Rica.

Ministerio de Agricultura y Ganadería (MAG). (2017). Principales Suelos de Costa Rica. Asociación Costarricense de la Ciencia del Suelo. Recuperado de http://www.mag.go.cr/bibioteca_virtual_ciencia/ suelos-cr.html

Ministerio de Ambiente Energía y Telecomunicaciones (MINAET). (2013). Mapa de tipos de bosque de Costa. San José, Costa Rica: Inventario Nacional 88 Forestal.

Montero, W. \& Denyer, P. (2011). Fallamiento neo tectónico de la península de Nicoya y su relación con el escape tectónico del antearco centroamericano. En: Revista Geológica de América Central, 45, 9-52.

Ortiz, E. \& Montoya, C. (2014). Atlas Digital de Costa Rica 2014 [CDROM]. Instituto Tecnológico de Costa Rica. Escuela de Ingeniería Forestal.

Oyola, N. (2009). Identificación de humedales del norte grande de chile utilizando técnicas geomáticas en imágenes satelitales Landsat. Universidad de Chile. (Proyecto de grado presentado como parte de los requisitos para optar al grado de Magíster en Áreas Silvestres y Conservación de la Naturaleza). Santiago, Chile.

Samper-Villarreal, J. \& Silva-Benavides, M. (2015). Complejidad estructural de los manglares de Playa Blanca, Escondido y Rincón de Osa, Golfo Dulce, Costa Rica. En: Revista de Biología Tropical, 63(1), 199-208. 
Iván Sanabria-Coto, Instituto, Milagro Carvajal-Oses, Rooel Campos-Rodríguez, Paola Solera-Steller. A Proposal for a Comprehensive Geographical Delimitation of the Mangrove of Nosara, Guanacaste, Costa Rica

Schaeffe-Novelli, Y., Cintrón-Morero, G., Soares, M. \& De-Rosas, T. (2000). Brazilian mangroves. En: Aquatic ecosystem Health and management, 3, 561-570.

Serrato, P. (2009). Clasificación fisiográfica del terreno a partir de la inclusión de nuevos elementos conceptuales. En: Revista Perspectiva Geográfica, 14, 181-218.

Servicio Nacional de Aguas Subterráneas Riego y Avenamiento (SENARA). (2016). Resumen litológico de los pozos: GA-56, GA-93, GA246, GA-250, GA-19, GA-116, GA-273, GA-2, GA-1, GA-3 de la base de datos de pozos.

Sistema Nacional de Áreas de Conservación (SINAC). (2014). Diagnóstico para el Plan General de Manejo del Refugio Nacional de Vida Silvestre Ostional. H. Acevedo y E. Vargas (eds.). Guanacaste, Costa Rica. . Sistema Nacional de Información Territorial (SNIT). (2017). Recuperado de http://www.snitcr.go.cr/.

Spotila, J., Marshall, J., Depew, K., Prince, P. \& Kennedy, L. (2016). Potential for geologic records of coseismic uplift and megathrust rupture along the Nicoya Peninsula, Costa Rica. En: Journal of Coastal Research, 32(2), 387-396.

Tuan Vo, Q., Oppelt, N., Leinenkugel, P. \& Kuenzer, C. (2013). Remote Sensing in Mapping Mangrove Ecosystems - An Object-Based Approach. En: Remote Sens, 5,. 183-201.

Ulloa, A., Aguilar, T., Goicoechea, C. \& Ramírez, R. (2011). Descripción, clasificación y aspectos geológicos de las zonas kársticas de Costa Rica. En: Revista Geológica de América Central, 45, 53-74.

Valverde, R., González, C., Piedra, L. \& García, J. (2016). Vulnerabilidad y adaptabilidad al ascenso del nivel del mar en humedales y poblaciones costeras: el manglar del Humedal Nacional Térraba-Sierpe de Osa, Costa Rica. En: Revista En Torno a la Prevención, 16, 7-16.

Woodroffe, K., Roger, S., Mckee, K., Lovelock, C., Mendelssohn, I. \& Saintilan, N. (2016). Mangrove Sedimentation and Response to Relative Sea-Level Rise. En: Annual Review of Marine Science, 8, 243266. DOI: 10.1146/annurev-marine-122414-034025.

Yáñez, A., Day, J., Twilley, R. \& Lara, A. (1998). Los ecosistemas de manglar frente al cambio climático global. En: Madera y Bosques, $.4,(2) .3-19$. 
Iván Sanabria-Coto, Instituto, Milagro Carvajal-Oses, Rooel Campos-Rodríguez, Paola Solera-Steller.

Propuesta para una Delimitación Geográfica Integral del Manglar de Nosara, Guanacaste, Costa Rica

Zaldívar, A., Herrera, J., Teutli, H., Hernández, C. \& Caamalsosa, R. (2010). Manglares. (138-139). En: Duran R. y M. Méndez (eds.). Biodiversidad y Desarrollo Humano en Yucatán. México: CICY, PPD-FMAM, CONABIO, SEDUMA.

Zamora-Trejos, P. \& Cortés, J. (2009). Los manglares de Costa Rica: el Pacífico norte. En: Biología Tropical, 57(3), 473-488. 